\title{
FITOTERAPIA
}

Fitoterapia 71 (2000) S124-S130

www.elsevier.com/locate/fitote

\section{Pro-cognitive activity induced in the rat by low doses of $R-(+)$-hyoscyamine}

\author{
C. Ghelardini*, N. Galeotti, A. Bartolini \\ Department of Pharmacology, Viale G. Pieraccini 6, 1-50139 Florence, Italy
}

\begin{abstract}
In the passive-avoidance test $R$ - $(+)$-hyoscyamine $\left(10-100 \mu \mathrm{g} \mathrm{kg}^{-1}\right.$ i.p. $)$ prevented amnesia induced by antimuscarinic treatment with AF-64A and benzhexol. The antiamnesic effect of $R$-(+)-hyoscyamine was comparable to that exerted by the cholinesterase inhibitor physostigmine $\left(0.2 \mathrm{mg} \mathrm{kg}^{-1}\right.$ i.p) and the $\mathrm{M}_{1}$ selective agonist $\mathrm{AF}-102 \mathrm{~B}\left(10 \mathrm{mg} \mathrm{kg}^{-1}\right.$ i.p.). In the social learning test, $R-(+)$-hyoscyamine $\left(10-100 \mu \mathrm{g} \mathrm{kg}^{-1}\right.$ i.p.) in adults rats, reduced the duration of active exploration of the familiar partner in the second session of the test similar to the nootropic drug piracetam $\left(30 \mathrm{mg} \mathrm{kg}^{-1}\right.$ i.p.). These results demonstrated the ability of $R-(+)$-hyoscyamine to modulate memory functions and suggest that $R-(+)$-hyoscyamine could be useful in the treatment of cognitive deficits. (C) 2000 Elsevier Science B.V. All rights reserved.
\end{abstract}

Keywords: $R-(+)$-Hyoscyamine; Acetylcholine releaser; Memory; Amnesia; Cholinergic system

\section{Introduction}

Cholinergic activity has long been associated with memory processes. Morphological and neurochemical studies of Alzheimer's disease, the major type of dementia, have revealed marked decreases in the cholinergic innervation of the cortex and hippocampus [1]. Drugs involving cholinergic stimulation alleviate cognitive dysfunctions in Alzheimer's disease [1]. On the other hand, cholinergic

\footnotetext{
* Corresponding author.
} 
blockade produces significant impairment in cognitive functions. A delay-dependent disruption following treatment with anticholinergic agents, appearing to resemble that occurring spontaneously in aged subjects and in Alzheimer patients, has been reported [3]. Ghelardini et al. [4], using microdialysis techniques, reported that $R$-(+)-hyoscyamine, at very low doses $\left(10-100 \mu \mathrm{g} \mathrm{kg}{ }^{-1}\right.$ i.p.), produced an increase in the acetylcholine ( $\mathrm{ACh})$ release from the rat cerebral cortex in vivo. Moreover, $R$ - $(+)$-hyoscyamine, at the same doses, is also able to prevent amnesia induced by scopolamine and hypoxia in the mouse passive-avoidance test [4]. On the basis of this experimental evidence we thought it useful to investigate if the protective effect exhibited by $R-(+)$-hyoscyamine in mice was extendible to rats by using both passive-avoidance and social learning tests.

\section{Experimental}

\subsection{Animals}

Wistar rats (90-110 g, 350-450 g) from Morini (San Polo d'Enza, Italy) breeding farms were used. Four rats were housed per cage. All experiments were carried out according to the guidelines of the European Community Council for experimental animal care.

\subsection{Intracerebroventricular injection technique}

Intracerebroventricular (i.c.v.) administration was performed under ether anesthesia according to the method described by Haley and McCormick [6] for mice, which we adapted for rats.

\subsection{Passive-avoidance test}

The test was performed according to the step-through method described by Jarvik and Kopp [7]. The apparatus consisted of a two-compartment acrylic box with a lighted compartment connected to a darkened one by a guillotine door. Rats, as soon as they entered the dark compartment, received a punishing electrical shock. For memory disruption, animals were injected with amnesic drugs: benzhexol or AF-64A.

\subsection{Social learning test}

The social learning test was performed according to Mondadori et al. [8]. Male Wistar rats (350-450 g) were used throughout the experiments and juvenile males (90-110 g) were used as social stimuli. The first day of the experiment, a juvenile rat was introduced into the adult male's cage and the time spent in social-investigatory behavior by the adult male within a 5-min fixed interval was recorded. After 24 
$\mathrm{h}$, either the same juvenile or an unfamiliar one was placed again into the mature male's cage and social investigatory behavior was recorded in a 5-min interval.

\subsection{Spontaneous activity meter (Animex)}

Locomotor activity in rats was quantified using an Animex activity meter Type $\mathrm{S}$ (LKB, Farad, Sweden). Every movement of the rats, which were placed on the top of the Animex activity meter, produced a signal due to variation in inductance and capacity of the apparatus resonance circuit. Then, signals were automatically converted to numbers. On the day of the experiment the rats were treated and then the cage, containing three rats, was put on the measuring platform. Activity counts were made for $5 \mathrm{~min}$.

\subsection{Rota-rod test}

The apparatus consisted of a base platform and a rotating rod (16 rev. $\left.\mathrm{min}^{-1}\right)$ with a non-slippery surface. The integrity of motor coordination was assessed on the basis of endurance time of the animals on the rotating rod. The animals were trained twice 1 day before the test. On the day of the test only the rats that were able to stay balanced on the rotating rod between 70 and $120 \mathrm{~s}$ (cut-off time) were selected for testing. The performance time was measured before and at various times after treatment.

\subsection{Drugs}

The following drugs were used: $R-(+)$-hyoscyamine was prepared according to Gualtieri et al. [5], benzhexol (Cyanamid), acetylethylcholine mustard hydrochloride (R.B.I.); AF-102B (Institute for Neurobiology Res., Brussels, Belgium); piracetam and physostigmine hemisulfate (Sigma).

\subsection{Statistical analysis}

All experimental results are given as the mean \pm S.E.M. Analysis of variance (ANOVA), followed by Fisher's Protected Least Significant Difference (PLSD) procedure for post-hoc comparison, was used to verify the significance between the two means. Data were analyzed with the StatView software for the Macintosh (1992). $P<0.05$ was considered significant.

\section{Results}

$R$-(+)-Hyoscyamine (10-100 $\mu \mathrm{g} \mathrm{kg}^{-1}$ i.p.) prevented amnesia induced by AF-64A ( 2 nmol per rat, i.c.v.; Fig. 1a) and benzhexol $\left(10 \mathrm{mg} \mathrm{kg}^{-1}\right.$ i.p.; Fig. 1b) in the rat passive-avoidance test, reaching entrance latency values comparable to those 

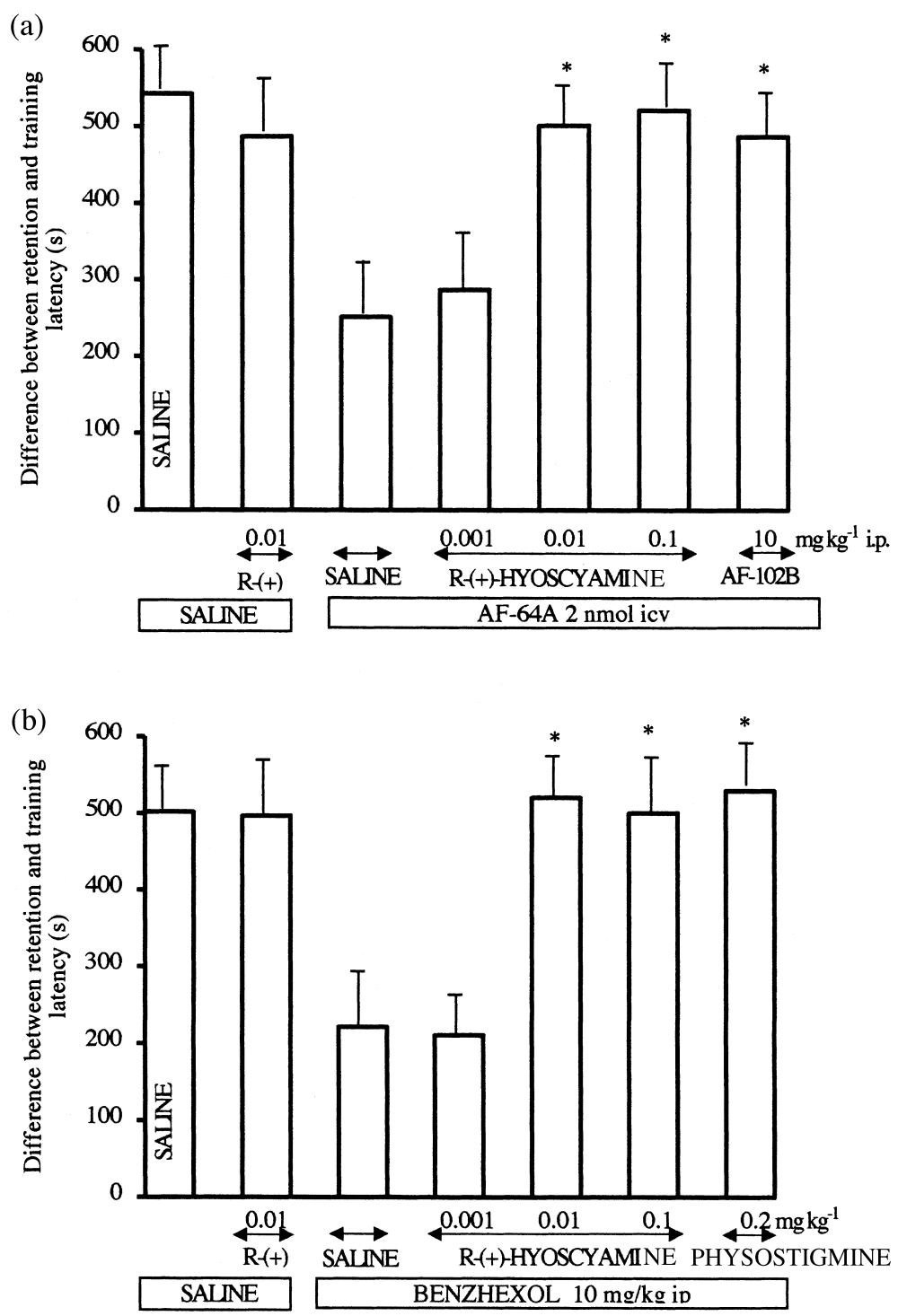

Fig. 1. Prevention by $R$ - $(+)$-hyoscyamine of amnesia induced by AF-64A (a) and benzhexol (b) in rat passive-avoidance tests. Each column represents the mean of at least eight rats. ${ }^{*} P<0.01$.

produced by saline-treated mice. Protection exerted in rats by $R-(+)$-hyoscyamine was comparable to that exerted by the $\mathrm{M}_{1}$ selective agonist AF-102B (10 mg kg-1 i.p.; Fig. 1a) and by the cholinesterase inhibitor physostigmine $\left(0.2 \mathrm{mg} \mathrm{kg}^{-1}\right.$ i.p.; Fig. 1b). AF-64A and benzhexol were injected, respectively, $4 \mathrm{~h}$ before and immediately after the training session. At active doses, $R-(+)$-hyoscyamine did not 


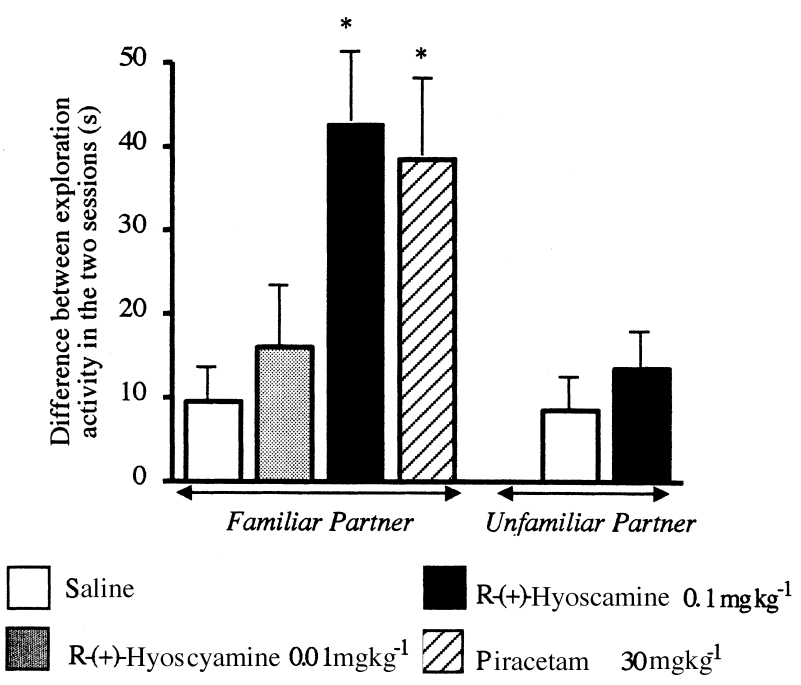

Fig. 2. Effect of $R-(+)$-hyoscyamine (i.p.) in rat social learning tests in comparison with piracetam. Each column represents the mean of six rats. ${ }^{*} P<0.01$.

enhance the entrance latency in unamnesic rats in comparison with the control group (Fig. 1a,b). There were no differences observed in the various entrance latencies of every group in the training session of the passive-avoidance test (data not shown).

In the social learning test adult rats were treated with $R$-(+)-hyoscyamine (10-100 $\mathrm{g} \mathrm{kg}^{-1}$ i.p.) and piracetam $\left(30 \mathrm{mg} \mathrm{kg}^{-1}\right.$ i.p.), or saline $20 \mathrm{~min}$ before the first session of the test. In the adult animals treated with $R-(+)$-hyoscyamine, the duration of active exploration of the familiar partner at the second pairing at $24 \mathrm{~h}$ was shortened in comparison with saline-treated rats (Fig. 2). No curtailment was observed if an unknown partner was presented (Fig. 2). At the dose of $1 \mu \mathrm{g} \mathrm{kg}^{-1}$ i.p. $R-(+)$-hyoscyamine was ineffective. In the same experimental conditions a nootropic drug, such as piracetam, also reduced the time spent on exploratory behavior (Fig. 2). All drugs used did not modify the duration of active exploration in the first session in comparison with saline-treated rats (data not shown).

It should be noted that $R$-(+)-hyoscyamine elicited its modulatory effect on cognitive processes without changing either gross behavior, motor coordination, or spontaneous motility, as revealed, respectively, by the rat rota-rod test (Table 1) and the rat Animex apparatus (data not shown). $R-(+)$-hyoscyamine, administered at the highest active doses, did not reduce the endurance time on the rotating rod in comparison with saline-treated mice (Table 1). In contrast, in the same experimental conditions, physostigmine $\left(0.2 \mathrm{mg} \mathrm{kg}^{-1}\right.$ i.p. $)$ reduced time spent by the animals on the rotating rod (Table 1$)$. The spontaneous motility of rats was unmodified by $R-(+)$ hyoscyamine administration $\left(100 \mu \mathrm{g} \mathrm{kg}^{-1}\right.$ i.p. $)$ as revealed by the Animex apparatus in comparison with saline-treated rats (data not shown). 
Table 1

Effect of $R-(+)$-hyoscyamine in comparison with physostigmine in rat rota-rod test

\begin{tabular}{|c|c|c|c|c|}
\hline & \multicolumn{4}{|c|}{ Endurance time on rota-rod } \\
\hline & \multirow[t]{2}{*}{ Before treatment } & \multicolumn{3}{|c|}{ After treatment } \\
\hline & & $15 \mathrm{~min}$ & $30 \mathrm{~min}$ & $45 \mathrm{~min}$ \\
\hline Saline (i.p.) & $\begin{array}{l}103.5 \pm 5.6 \\
(11)\end{array}$ & $\begin{array}{l}99.7 \pm 7.2 \\
(11)\end{array}$ & $\begin{array}{l}102.9 \pm 5.9 \\
(11)\end{array}$ & $\begin{array}{l}96.3 \pm 4.9 \\
(11)\end{array}$ \\
\hline $\begin{array}{l}R-(+) \text {-Hyoscyamine } \\
\quad\left(0.1 \mathrm{mg} \mathrm{kg}^{-1} \text { i.p. }\right)\end{array}$ & $\begin{array}{l}98.5 \pm 6.9 \\
(10)\end{array}$ & $\begin{array}{l}103.6 \pm 7.7 \\
(10)\end{array}$ & $\begin{array}{l}96.2 \pm 8.3 \\
(10)\end{array}$ & $\begin{array}{l}101.2 \pm 8.6 \\
(10)\end{array}$ \\
\hline $\begin{array}{l}\text { Physostigmine } \\
\qquad\left(0.2 \mathrm{mg} \mathrm{kg}^{-1} \text { i.p. }\right)\end{array}$ & $\begin{array}{l}102.4 \pm 4.5 \\
(10)\end{array}$ & $\begin{array}{l}65.3 \pm 8.1^{*} \\
(10)\end{array}$ & $\begin{array}{l}65.7 \pm 7.3^{*} \\
(10)\end{array}$ & $\begin{array}{l}87.4 \pm 8.4^{*} \\
(10)\end{array}$ \\
\hline
\end{tabular}

${ }^{*} P<0.05$ in comparison with the respective pre-test value. The number of rats is shown in parentheses.

\section{Discussion}

The present results describe the effects observed with $R-(+)$-hyoscyamine on experimentally impaired memory and unimpaired learning in rats. $R-(+)$-Hyoscyamine has been demonstrated to ameliorate cognitive processes, not only by preventing amnesia induced by pharmacological treatments in passive-avoidance tests, but also by producing procognitive activity in a social learning task. A blockade of the cholinergic system produces memory impairment [2]. Disruption of the cholinergic system can also be obtained by the use of cholinotoxins. The i.c.v. injection of the ethylcholine aziridinium ion (AF-64A), a selective cholinotoxin, causes a deficient performance in a rat passive avoidance task and a delayed alteration task in the T-maze test [9].

Microdialysis studies show that $R-(+)$-hyoscyamine is able to increase ACh release from rat cerebral cortex [4] and hippocampus (data not shown), two cerebral structures highly involved in the modulation of cognitive processes [1]. Therefore, it is not unexpected that $R-(+)$-hyoscyamine is able to prevent amnesia induced by antimuscarinic drugs, by disruption of the cholinergic neurons through the antimuscarinic toxin AF-64A.

The time-course of the antiamnesic activity of $R-(+)$-hyoscyamine is equal to that observed for its antinociceptive action, reaching its maximum between 15 and $30 \mathrm{~min}$ after injection (data not shown). Therefore, in the learning and memory experiments $R-(+)$-hyoscyamine was administered $20 \mathrm{~min}$ before the training session.

In the passive avoidance test improved cognition in animals with no memory impairment is difficult to demonstrate. As a matter of fact, not only $R-(+)$-hyoscyamine but also well known nootropic drugs such as piracetam do not facilitate memory in unamnesic animals [2]. However, a procognitive activity of $R$ - $(+)$-hyoscyamine was unmasked by using a social learning test in which adults rats with 
unimpaired memory were used. $R-(+)$-hyoscyamine, as well as piracetam, benefit cognitive performance by prolonging the time physiologically spent by rats to delete mnemonic information.

$R-(+)$-hyoscyamine, at the highest doses used, did not impair motor coordination as revealed by the rota-rod test or modify spontaneous motility as indicated by the Animex apparatus. Furthermore, $R-(+)$-hyoscyamine did not elicit the typical cholinergic symptoms produced by injection of direct postsynaptic muscarinic agonists. In other words, $R-(+)$-hyoscyamine is able to counteract amnesia and to exert a procognitive activity in a more physiological manner than the cholinergic activators, such as physostigmine or AF-102B, used as reference drugs. In conclusion, these results indicate the ability of $R-(+)$-hyoscyamine to modulate memory processes. On these bases, $R-(+)$-hyoscyamine could be considered a new potential antiamnesic drug useful in the treatment of cognitive disorders.

\section{References}

[1] Bartus RT, Dean RL, Beer B, Lippa AS. Science 1982;217:408.

[2] Coyle MJ. A cholinergic hypothesis for Alzheimer's disease. London: Pergamon Press, 1995.

[3] Duetsch JA. Science 1971;174:788.

[4] Ghelardini C, Gualtieri F, Romanelli MN et al. Neuropharmacology 1997;36:281.

[5] Gualtieri F, Romanelli MN, Scapecchi S et al. Med Chem Res 1991;1:52.

[6] Haley TJ, McCormick WG. Br J Pharmacol Chemother 1957;12:12.

[7] Jarvik ME, Kopp R. Psychol Rep 1967;21:221.

[8] Mondadori C, Preiswerk G, Jaekel J. Pharmacol Commun 1992;2:93.

[9] Nakahara N, Iga Y, Mizobe F, Kawanishi G. Jpn J Pharmacol 1988;48:121. 